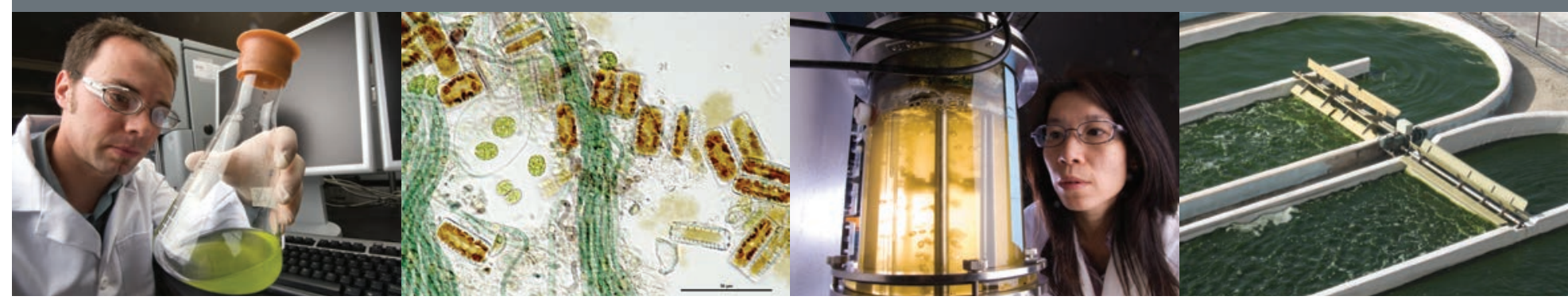

NREL is involved in several algal biofuels projects with national and international partners, including a series of projects funded through NREL's Laboratory Directed Research and Development (LDRD) program. These projects are addressing the challenges that accompany the algal biofuels production process.

\section{Algal Biofuels}

Microalgae-photosynthetic microorganisms capable of converting atmospheric $\mathrm{CO}_{2}$ to biomass and oil-offer great promise to contribute a significant portion to our renewable fuels and meet the mandate to dramatically reduce our dependence on the world's dwindling natural energy resources.

NREL's current algal biofuels program builds on the expertise and knowledge acquired from the research into microalgal biofuels done by the Aquatic Species Program, which was established in 1978 under funding from the U.S. Department of Energy (DOE).

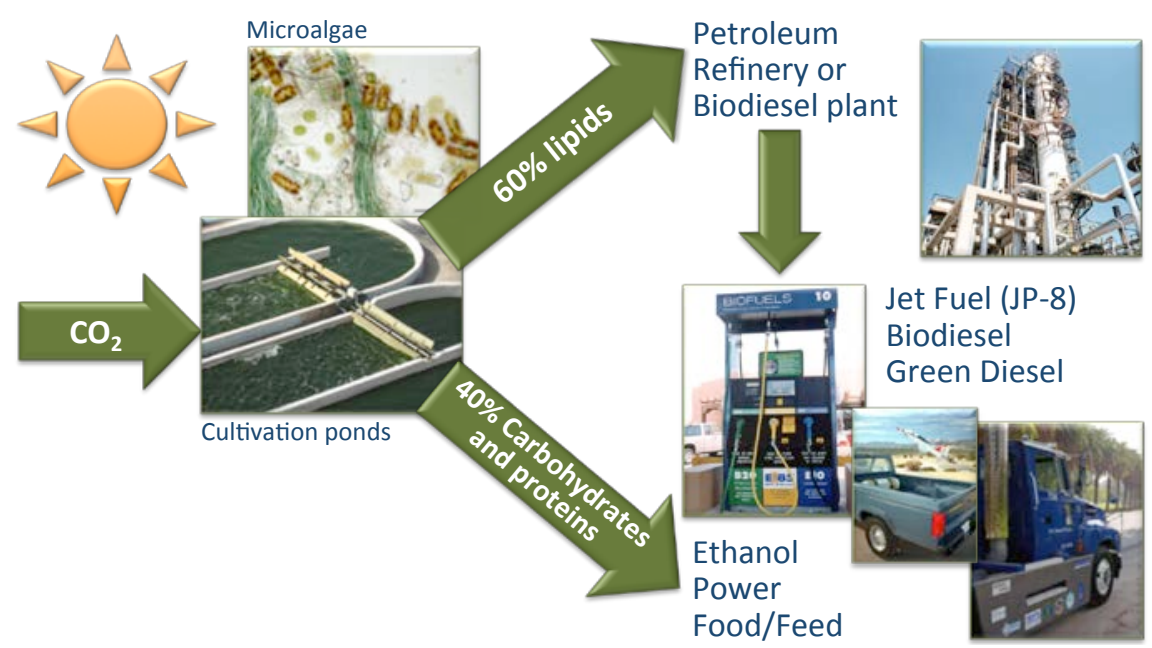

Summary of the current algal biomass-to-biofuels product streams. (Adapted from Pienkos and Darzins, 2009.)

\section{The Promise}

Algal biomass-derived biofuels promise great advantages, such as a high amount of oil productivity per acre; use of nonarable land and a wide variety of water sources; the mitigation of greenhouse gas emissions; and a good potential for use in producing both biofuels and other valuable co-products.

\section{The Challenges}

Despite its huge potential, the technology of using microalgae as biomass feedstocks for advanced biofuels faces major challenges from both technical and economic barriers. These include developing suitable algal strains and cultivation parameters, developing processes to harvest the biomass and extract the oils, and rendering the entire process economical.

Past work has provided a solid foundation for algal biofuels research, making it possible for NREL to rebuild an algal biofuels program, though in a very different form. To produce algal biofuels economically and sustain that production at scale, we are gathering a greater understanding of the underlying biological and engineering principles. 


\section{Algal Biofuels Projects and Partnerships}

NREL is currently involved in several algal biofuels projects addressing different aspects of algal biofuels research and development (R\&D) that are funded by NREL LDRD, DOE, or in collaboration with commercial partners.

\section{Establishment of a 400+ Bioenergy-Focused Microalgae Strain Collection Using Rapid, High- Throughput Methodologies}

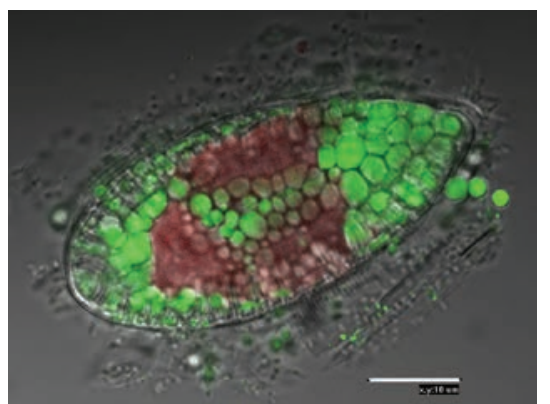

NREL, the Colorado School of Mines, and the National Research Council of Canada have established a bioenergyfocused strain collection.

High-throughput technologies are used to discover new novel

microalgae strains that can be used for biofuel and bioproduct applications. Over 400 microalgal strains have been generated using novel strain isolation methods and a culture collection that is now being screened for isolates with high-growth and lipid-accumulation properties. The culture collection spans strains from the southwestern United States to isolates from northern latitudes, including marine, fresh-water, and hyper-saline environments. These projects are funded by the Colorado Center for Biorefining and Biofuels (C2B2) and DOE.

\section{Molecular Foundations of Algal Biofuel Production: Proteomics and Transcriptomics of Algal Oil Production}

NREL is combining a proteomics and transcriptomics approach to fully characterize the molecular foundation of algal biofuels production with external environmental conditions in an oilaccumulating green alga. The proteomics work was initiated under a project funded by the U.S. Air Force Office of Scientific Research (AFOSR) and aims to answer fundamental algal
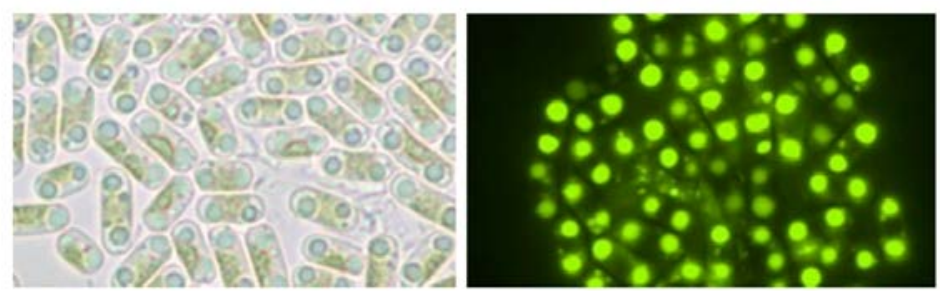

biology questions regarding oil production that could lead to the development of cost-effective, algal-based jet fuel. NREL is combining the proteomics work with an internally-funded transcriptomics study to get a better understanding of the changes that occur during transition to high-lipid growth conditions. These technologies provide NREL with information that can be used to identify genes and pathways involved in biofuel production and to guide strain improvement strategies.

To further develop an algal genetic toolbox, NREL has identified and tested promoter-gene sequences isolated from a green-algal species and is taking advantage of the sequencing information of the chloroplast genome to increase
Nitrogen Replete

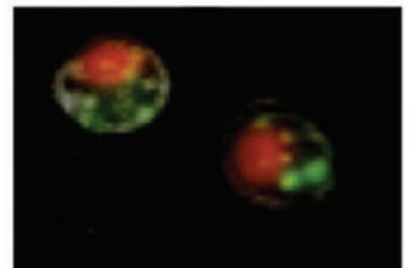

\section{Nitrogen Deplete}

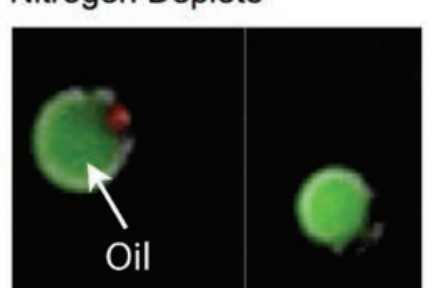

lipid production. This work will expand the genetic tool box for green-algal systems and allow for full development of metabolic engineering efforts from molecular "omics" studies.

\section{Evaluation of Regulated Enzymatic Disruption of Algal Cell Walls as an Oil Extraction Technology}

NREL is characterizing cell-wall-degrading enzymes for their activity on disrupting algal cell walls sufficiently to allow internal oil bodies to escape and be easily harvested. This technology could be a simple and economic option for recovery of lipids from algal biomass. 


\section{Development of Novel Microalgal Production and Downstream Processing Technologies for Alternative Biofuels Application}

NREL is part of the DOE-funded Sustainable Algal Biofuels Consortium (SABC), working on the development of several technologies for use in alternative biofuels applications, using both thermochemical and biochemical conversion routes. Researchers are focused on testing the acceptability of algal biofuels as replacements for petroleum-based fuels. Specific tasks include investigating biochemical conversion of algae to both lipid- and carbohydrate-based fuels and products, and analyzing the physical and chemical properties of algal fuels and fuel intermediates.

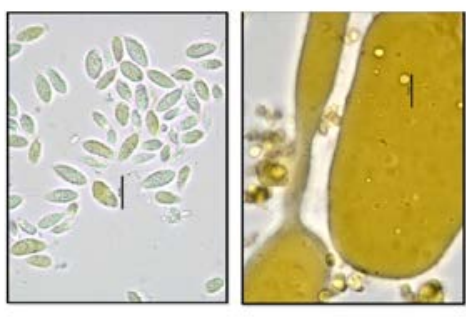

Physical appearance of algae before and after biochemical conversion, showing large oil droplets formed during the reaction
NREL also works on the development of costeffective, thermochemical oil extraction and conversion processes. Projects include a feasibility study of proven thermochemical conversion technologies to transform algal biomass into fuel or related intermediate products. Funded by DOE, this work is establishing proof-ofconcept for thermochemical processes.

\section{Efficient Use of Algal Biomass Residues for Anaerobic Digestion Biopower Production Coupled with Nutrient Recycle}

NREL, together with Washington State University, is investigating the optimization of biogas production from algal residues via anaerobic digestion. In this project, research is being carried out to understand effluent treatment requirements and the fate and bio-availability of nitrogen and phosphorus following anaerobic digestion, as well as testing the ability of recycled nutrients to support algal growth.

\section{Development of Robust and High-Throughput Characterization Technologies for Algal Biomass}

NREL researchers are developing methods for the analysis of biofuel process-relevant components in algal biomass. These methods will allow researchers to assess the efficiency of the overall algal biofuels production process through the use of techno-economic analyses. This will keep NREL at the forefront of compositional analysis of novel feedstocks and allow for accurate quantification of important constituents in a process. In addition, NREL is developing high-throughput spectroscopic-prediction methods to predict the composition of algal biomass from model organisms and culture collection strains in minutes rather than days.

\section{Techno-Economic Assessment of Algal Biofuels Processes}

Several DOE-funded projects, including consortia like National Alliance for Advanced Biofuels and Bioproducts (NAABB) and $S A B C$, are studying the viability of algae as a biofuels feedstock in the context of resource availability and techno-economic barriers and opportunities. The NREL team provides data for the modeling of the process and final fuel costs.
Process for making biofuels from microalgae. (Pienkos, P.T., et al. (2011) “Making Biofuel from Microalgae." American Scientist, 99(6): 474 DOI: 10.1511/2011.93.474)

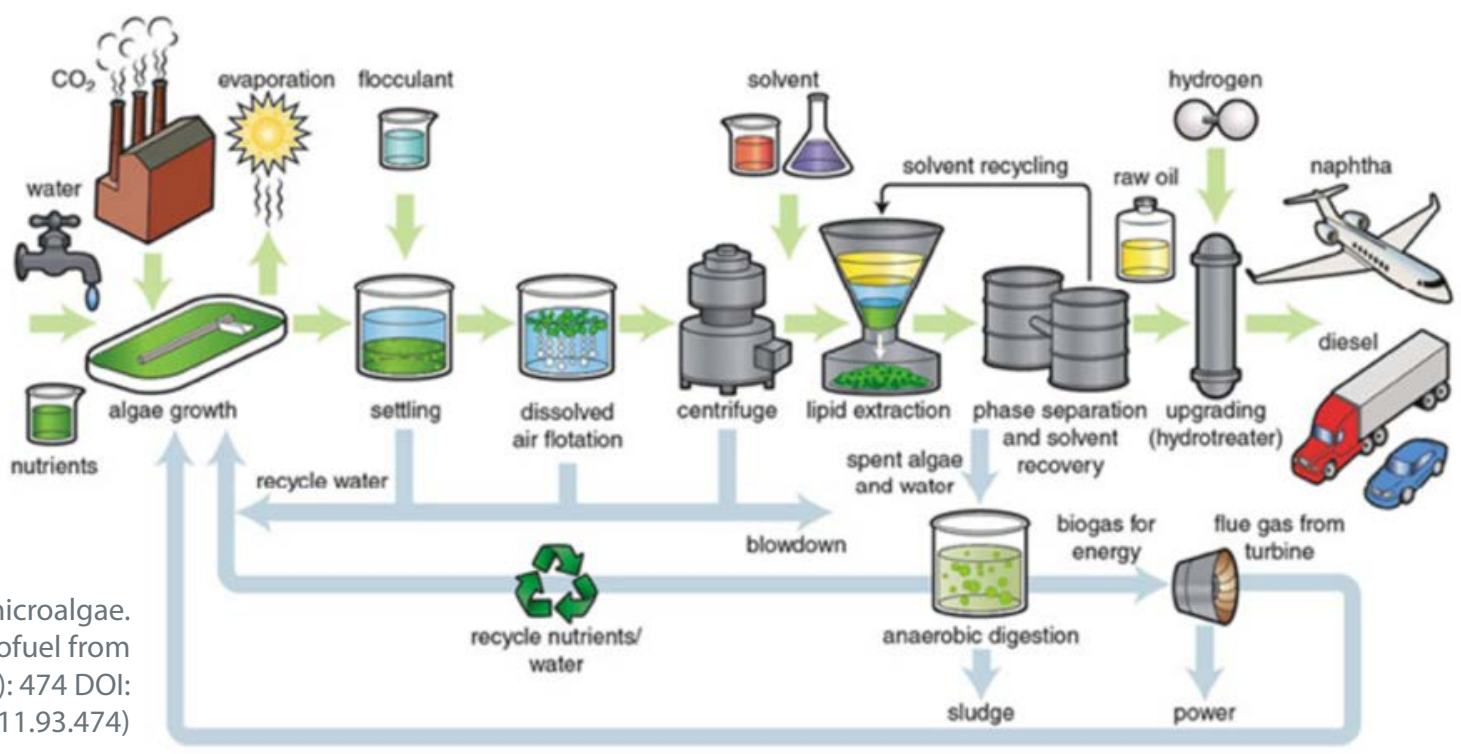




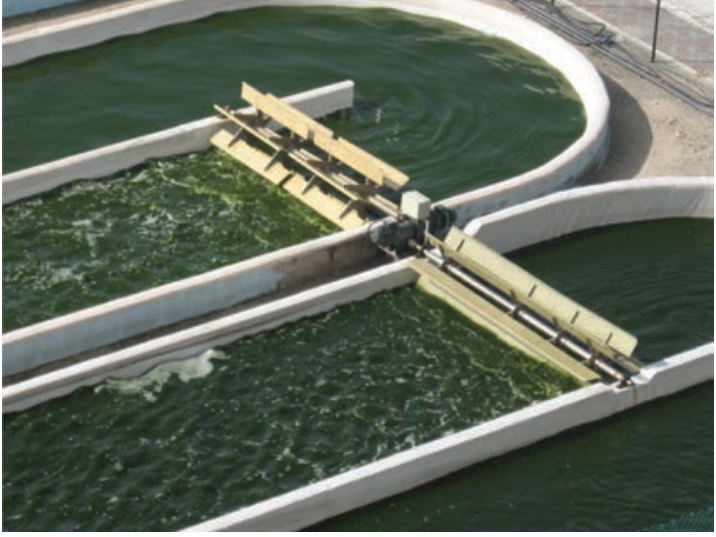

Sheehan et al. (1998) presaged the current revival in this field, concluding the ASP close-out report with the following:

"... this report should be seen not as an ending, but as a beginning. When the time is right, we fully expect to see renewed interest in algae as a source of fuels and other chemicals. The highlights presented here should serve as a foundation for these future efforts."

\section{High Impact Publications}

Sheehan, J., et al. (1998). "A Look Back at the U.S. Department of Energy's Aquatic Species Program: Biodiesel from Algae." Close-Out Report. Golden, CO: National Renewable Energy Laboratory.

Pienkos, P. T. and Darzins, A. (2009). "The Promise and Challenges of Microalgal-Derived Biofuels." Biofuels, Bioproducts and Biorefining, (3:4); pp. 431-440.

Pienkos, P.T., et al. (2011). "Making Biofuel from Microalgae," American Scientist, 99(6): 474 DOI: 10.1511/2011.93.474.
Elliott, L.G., et al. (2012). "Establishment of a Bioenergy-Focused Microalgal Culture Collection." Algal Research, DOI: 10.1016/j.algal.2012.05.002.

Guarnieri, M.T., et al. (2011). “Examination of Triacylglycerol Biosynthetic Pathways via De Novo Transcriptomic and Proteomic Analyses in an Unsequenced Microalga." PLOS ONE, 6(10), e25851.

Laurens, L. ML., et al. (2012). "Algal Biomass Constituent Analysis: Method Uncertainties and Investigation of the Underlying Measuring Chemistries." Analytical Chemistry, 84(4): 1879.

Davis, R., et al. (2011). "Techno-Economic Analysis of Autotrophic Microalgae for Fuel Production." Applied Energy, 88(10), 3524-3531.

\section{Contacts}

Philip Pienkos, Principal Group Manager

Applied Scienes

National Bioenergy Center

Philip.Pienkos@nrel.gov

\section{National Renewable Energy Laboratory}

15013 Denver West Parkway, Golden, CO 80401

303-275-3000 • www.nrel.gov

NREL is a national laboratory of the U.S. Department of Energy Office of Energy Efficiency and Renewable Energy Operated by the Alliance for Sustainable Energy, LLC

NREL/BR-5100-56309 • September 2012

Printed with a renewable-source ink on paper containing at least 50\% wastepaper, including $10 \%$ post consumer waste.

\section{Credits}

Front page (L to R): Pat Corkery, NREL/PIX 15592; Photo from Lee Elliott, Colorado School of Mines; Pat Corkery, NREL/PIX16312; Photo from Nature Beta Technologies Ltd, Eilat, Israel, subsidiary of Nikken Sohonsh a Co. Gifu. Japan, NREL/PIX 22155. Page 2 (from top): Photo from Lee Elliott, Colorado School of Mines; Michael Guarnieri, NREL; Photo from Lee Elliott, Colorado School of Mines. Page 3: Nicholas Sweeney, NREL. Page 4: Photo from Nature Beta Technologies Ltd, Eilat, Israel, subsidiary of Nikken Sohonsha Co. Gifu. Japan, NREL/PIX 22155. 